\title{
A cryogenic ice setup to simulate carbon atom reactions in interstellar ices
}

Cite as: Rev. Sci. Instrum. 91, 054501 (2020); https://doi.org/10.1063/5.0003692

Submitted: 04 February 2020 . Accepted: 14 April 2020 . Published Online: 04 May 2020

(iD D. Qasim, M. J. A. Witlox, G. Fedoseev, (D) K.-J. Chuang, (D) T. Banu, (D) S. A. Krasnokutski, (D) s. loppolo, (D) J. Kästner, (D) E. F. van Dishoeck, and (D) H. Linnartz

\section{ARTICLES YOU MAY BE INTERESTED IN}

SURFRESIDE ${ }^{2}$ : An ultrahigh vacuum system for the investigation of surface reaction routes of interstellar interest

Review of Scientific Instruments 84, 073112 (2013); https://doi.org/10.1063/1.4816135

Design and implementation of a J-coupled spectrometer for multidimensional structure and relaxation detection at low magnetic fields

Review of Scientific Instruments 91, 054103 (2020); https://doi.org/10.1063/1.5130391

Surface temperature estimation in determined multi-wavelength pyrometry systems Review of Scientific Instruments 91, 054901 (2020); https://doi.org/10.1063/5.0005676

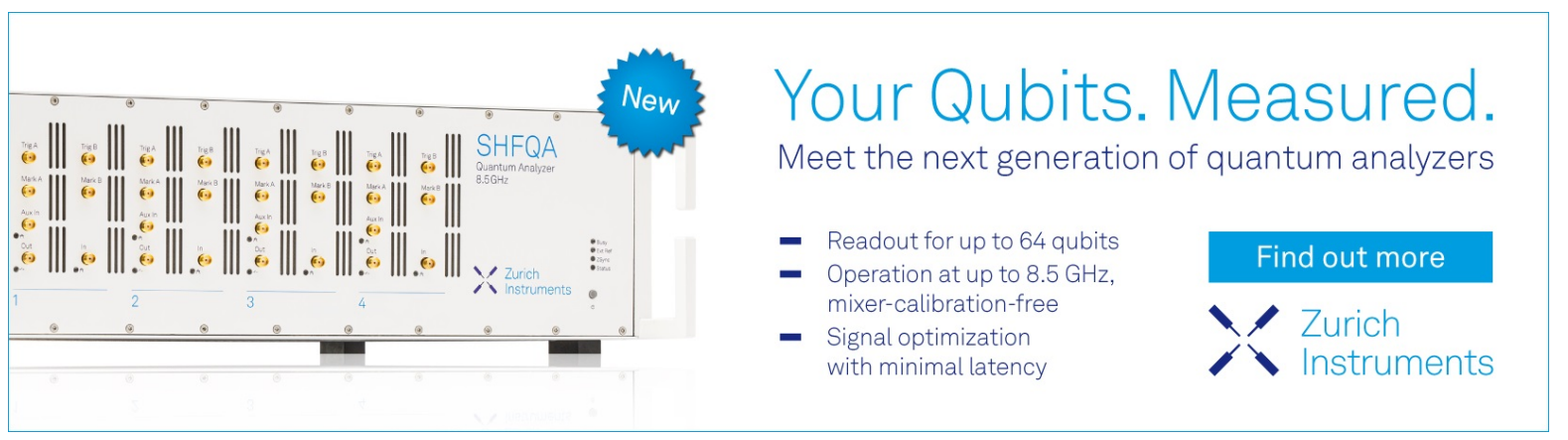




\title{
A cryogenic ice setup to simulate carbon atom reactions in interstellar ices
}

\author{
Cite as: Rev. Sci. Instrum. 91, 054501 (2020); doi: 10.1063/5.0003692 \\ Submitted: 4 February 2020 - Accepted: 14 April 2020 • \\ Published Online: 4 May 2020
}

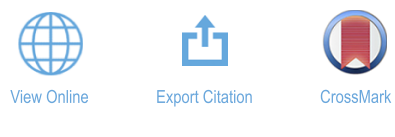
D. Qasim,
M. J. A. Witlox, ${ }^{2}$
'2. Fedoseev,' K.-J. Chuang,
T. Banu,
S. A. Krasnokutski,
S. Ioppolo,
J. Kästner,
E. F. van Dishoeck,
and $\mathrm{H}$. Linnartz

\begin{abstract}
AFFILIATIONS
${ }^{1}$ Laboratory for Astrophysics, Leiden Observatory, Leiden University, P.O. Box 9513, NL-2300 RA Leiden, The Netherlands

${ }^{2}$ Fine Mechanical Department, Leiden Institute for Physics Research (LION), Niels Bohrweg 2, NL-2333 CA Leiden, The Netherlands

${ }^{3}$ Laboratory Astrophysics Group of the Max Planck Institute for Astronomy at the Friedrich Schiller University Jena,

Institute of Solid State Physics, Helmholtzweg 3, D-07743 Jena, Germany

${ }^{4}$ Institute for Theoretical Chemistry, University of Stuttgart, D-70569 Stuttgart, Germany

${ }^{5}$ School of Electronic Engineering and Computer Science, Queen Mary University of London, Mile End Road, London El 4NS, United Kingdom

${ }^{6}$ Leiden Observatory, Leiden University, P.O. Box 9513, NL-2300 RA Leiden, The Netherlands
\end{abstract}

a) Author to whom correspondence should be addressed: dqasim@strw.leidenuniv.nl

\begin{abstract}
The design, implementation, and performance of a customized carbon atom beam source for the purpose of investigating solid-state reaction routes in interstellar ices in molecular clouds are discussed. The source is integrated into an existing ultrahigh vacuum setup, SURFace REaction SImulation DEvice (SURFRESIDE ${ }^{2}$ ), which extends this double atom (H/D, O, and N) beamline apparatus with a third atom (C) beamline to a unique system that is fully suited to explore complex organic molecule solid-state formation under representative interstellar cloud conditions. The parameter space for this system is discussed, which includes the flux of the carbon atoms hitting the ice sample, their temperature, and the potential impact of temperature on ice reactions. Much effort has been put into constraining the beam size to within the limits of the sample size with the aim of reducing carbon pollution inside the setup. How the C-atom beam performs is quantitatively studied through the example experiment, $\mathrm{C}+{ }^{18} \mathrm{O}_{2}$, and supported by computationally derived activation barriers. The potential for this source to study the solid-state formation of interstellar complex organic molecules through $\mathrm{C}$-atom reactions is discussed.
\end{abstract}

Published under license by AIP Publishing. https://doi.org/10.1063/5.0003692

\section{INTRODUCTION}

Complex organic molecules (COMs; carbon and hydrogen containing molecules with at least six atoms) have been detected in the cold and lightless environments of prestellar and starless molecular cloud cores (i.e., in the dark interstellar regions that are shrouded by dust), in addition to other astrophysical environments. ${ }^{1-3}$ Threecarbon COMs have now been observed in star-forming regions toward both high-mass ${ }^{4,5}$ and low-mass ${ }^{6}$ sources. Astrochemical models generally assume that a majority of the detected COMs in such surroundings originate from radical-induced surface reactions, in which the radicals are of the molecular form. ${ }^{7,8}$ This is supported by a series of recent laboratory and theoretical investigations of solid-state reactions, such as $\mathrm{HCO}, \mathrm{CH}_{3} \mathrm{O}$, and $\mathrm{CH}_{2} \mathrm{OH}$ recombinations, in which the radicals are formed by addition and abstraction reactions within the $\mathrm{CO}$ hydrogenation route.

Another solid-state pathway that offers a route to larger COMs is through direct carbon atom chemistry. This route has been proposed in theoretical works, ${ }^{14-17}$ applied to observational studies, ${ }^{18}$ and applied recently in astrochemical models. ${ }^{19}$ Neutral atomic carbon derived from the gas-phase is one of the most abundant elements in space ${ }^{20-22}$ and is primarily available during the early period of ice formation (i.e., before it reacts to form CO gas). ${ }^{23-25}$ The laboratory study of $\mathrm{C}$-atom chemistry under conditions representative 
of cold molecular clouds [i.e., ground state atomic carbon on $10 \mathrm{~K}$ surfaces in an ultrahigh vacuum (UHV) environment] has turned out to be very challenging, as it is experimentally difficult to produce an intense beam of largely ground state atomic carbon. This is a reason why there is little known regarding the role and relevance of $\mathrm{C}$-atom addition reactions in solid-state astrochemical processes. Recent laboratory works have demonstrated how atomic carbon can react to form simple radicals ${ }^{26,27}$ and $\mathrm{COMs}^{28}$ within liquid helium droplets. The present work extends this with the first ice system capable of studying $\mathrm{C}$-atom chemistry reactions in interstellar ice analogs.

The focus here is on the design, implementation, and characterization of an atomic carbon source into an existing atomic beamline setup, SURFace REaction SImulation DEvice (SURFRESIDE ${ }^{2}$ ), which is dedicated to studying molecular cloud surface reactions. The experimental details of this setup are described elsewhere. ${ }^{29}$ SURFRESIDE ${ }^{2}$ has been used to show how $\mathrm{H}_{2} \mathrm{O}, \mathrm{CO}_{2}$, and COMs can form under interstellar cloud conditions. ${ }^{9,11,30,31}$ The two available atomic beamlines currently permit the formation of a number of radicals, including $\mathrm{H} / \mathrm{D}, \mathrm{N}, \mathrm{O}, \mathrm{OH}$, and $\mathrm{NH}_{x}$. The addition of an atomic carbon source further extends the possibilities of studying COM formation by the accretion of atoms and small radicals, which is representative of the low density phase of molecular clouds where atoms are not yet largely locked up into molecules. . $^{2,33}$

The original design of the atomic carbon source is found in the work by Krasnokutski and Huisken, ${ }^{34}$ and the source discussed in this article is a customized SUKO-A 40 from Dr. Eberl MBEKomponenten GmbH (MBE), patent number DE 102014009755 A1. The design of the tantalum tube that is filled with graphite powder can be found in the works by Krasnokutski and Huisken ${ }^{34}$ and Albar et al. ${ }^{35}$ Heating of the tube causes the carbon atom to sublimate and react with tantalum to produce tantalum carbide, resulting in the conversion of molecular carbon into atomic carbon. Thus, the advantage of this source is that it essentially produces $\mathrm{C}$-atoms rather than $\mathrm{C}_{x}$ clusters $\left(<1 \% \mathrm{C}_{2}\right.$ and $\mathrm{C}_{3}$ molecules) ${ }^{34}$ Additionally, carbon atoms are formed by thermal evaporation rather than "energetic" processing. Therefore, we expect the formation of only ground state $\mathrm{C}\left({ }^{3} \mathrm{P}\right)$ atoms with moderate kinetic energies. The implementation, design, and calibration measurements of the source are described in Sec. II. Its performance, shown through example reactions that are considered relevant from an astronomical perspective and useful for calibration purposes, is presented in Sec. III. The results are interpreted following computationally calculated activation barriers that are briefly discussed. Section IV discusses how this source can be used to investigate astrochemically relevant surface reactions and how it can contribute to the science proposed with the upcoming James Webb Space Telescope (JWST). Section V lists the concluding remarks by summarizing the pros and cons of the new setup described here.

\section{SURFRESIDE ${ }^{3}$ AND ATOMIC CARBON SOURCE DESCRIPTION}

The new C-atom beamline is implemented into an existing setup, SURFRESIDE ${ }^{2}$, which has been described in detail before. ${ }^{2}$ The extended system, SURFRESIDE ${ }^{3}$, is shown in the $3 \mathrm{D}$ representation in Fig. 1. This UHV system allows the growth of interstellar ice analogs on a sample surface for temperatures as low as

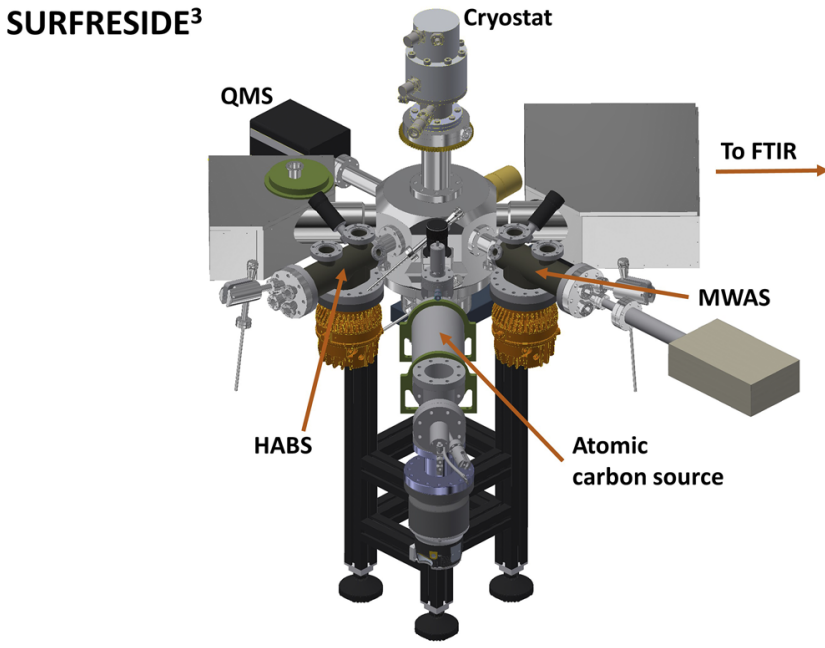

FIG. 1. A three atomic beam line system, including the new $\mathrm{C}$-atom source introduced here. The three atomic beam lines are capable of generating $H / D, N, O$, and $\mathrm{C}$-atoms, in addition to small radicals (e.g., $\mathrm{OH}, \mathrm{NH}$ ). It also contains two regular deposition lines. Both pre-deposition and co-deposition experiments can be performed. RAIRS and TPD-QMS are used as diagnostic tools.

$8 \mathrm{~K}$ using a closed-cycle helium cryostat. It comprises three atomic beam lines. The Hydrogen Atom Beam Source (HABS) ${ }^{36-38}$ and Microwave Atom Source (MWAS; Oxford Scientific Ltd.) beamlines have an angle of $45^{\circ}$ to the surface normal of the sample. The $\mathrm{C}$-atom source is mounted in between the HABS and the MWAS and faces the plane of the surface of the ice substrate perpendicularly. The result of impacting $\mathrm{H} / \mathrm{D}$-atoms by the $\mathrm{HABS}^{36-38}$ and/or $\mathrm{H} / \mathrm{D}-, \mathrm{O}-$, and $\mathrm{N}$-atoms and molecular radicals by the MWAS, and/or C-atoms by the new C-atom source is monitored using reflection absorption infrared spectroscopy (RAIRS) and/or temperature programmed desorption-quadrupole mass spectrometry (TPD-QMS). RAIRS allows monitoring of the formation of reaction products in situ, as well as quantitative measurements of the newly formed products using a Fourier Transform Infrared Spectrometer (FTIR). TPD-QMS is complementary to RAIRS, as it exploits the desorption temperature, mass-to-charge $(\mathrm{m} / \mathrm{z})$ value, and electron impact induced fragmentation pattern of the desorbed species to identify newly formed ice products. SURFRESIDE ${ }^{3}$ is unique, as it allows us to operate three different atomic beam lines simultaneously.

Ices are grown on the gold-plated substrate that is positioned vertically in the center of the main chamber of SURFRESIDE ${ }^{3}$, which reaches a base pressure of $\sim 3-4 \times 10^{-10}$ mbar at the start of each experiment. The surface is positioned such that it directly faces the $\mathrm{C}$-atom source beam. A substrate temperature range of $8-450 \mathrm{~K}$ is achieved by usage of a closed-cycle helium cryostat and resistive heating. The substrate temperature is probed by a silicon diode sensor that has an absolute accuracy of $0.5 \mathrm{~K}$.

\section{A. Design of the $\mathrm{C}$-atom line}

Figure 2 illustrates the cross section of the $\mathrm{C}$-atom source stainless steel chamber, which has a base pressure of $\sim 2 \times 10^{-9} \mathrm{mbar}$ 


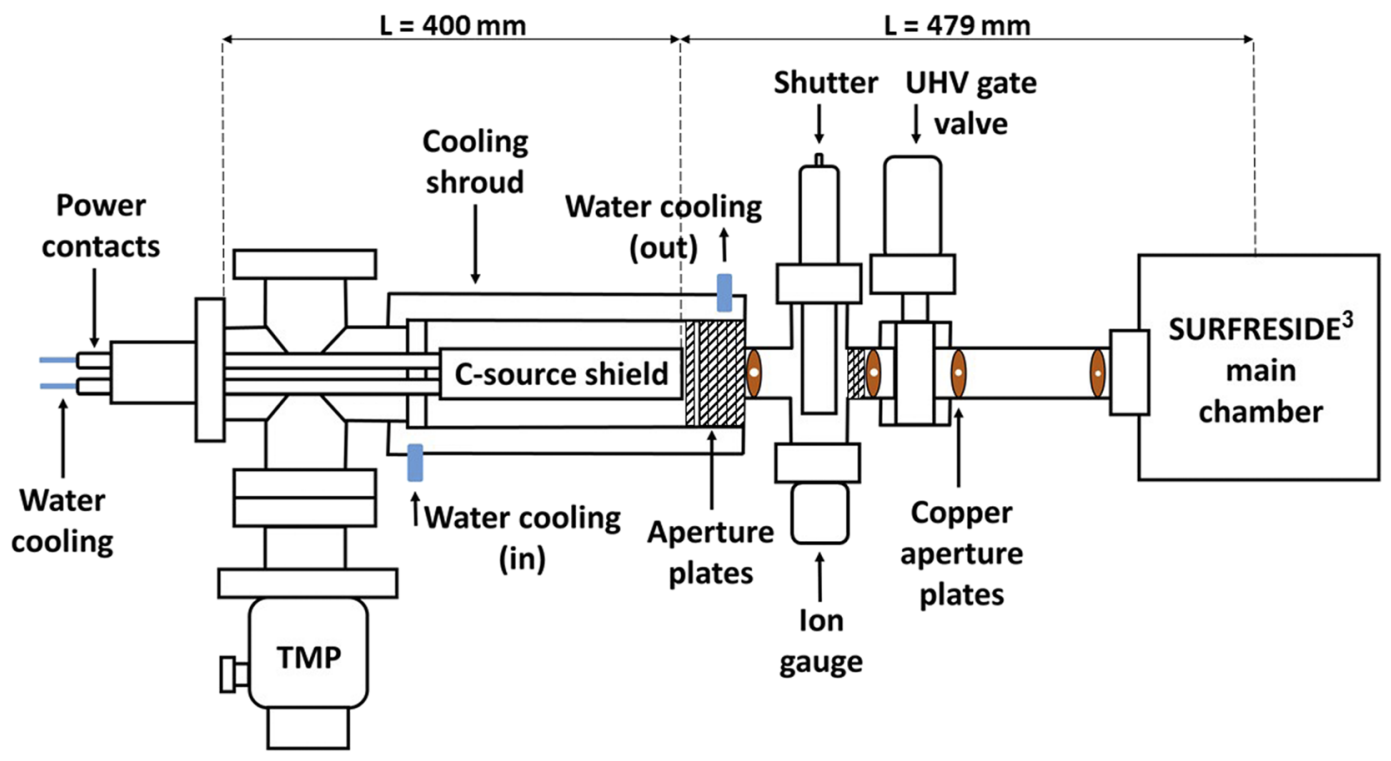

FIG. 2. Side view schematic of the atomic carbon source vacuum chamber.

when the source is at its standby current of $40 \mathrm{~A}$. Two watercooled power contacts are used to heat the source by means of a dc power supply that produces up to $1500 \mathrm{~W}$ (Delta Elektronika, SM 15-100).

The source is inserted into the vacuum chamber through a 4way cross (CF 63). At the bottom of the cross hangs a turbomolecular pump attached to an adapter (Leybold 350i, $290 \mathrm{l} / \mathrm{s}$ for $\mathrm{N}_{2}$, CF 100). As shown in Fig. 2, the pump is placed behind the source to keep it at a distance from the carbon atom beam, as carbon deposits may stick and potentially harm the pump blades by applying weight to them. A water-cooled shroud is attached to the right flange of the 4-way CF 63 cross to prevent surrounding components from melting, as operating temperatures are around $2030^{\circ} \mathrm{C}$. A tantalum shield is placed around the $\mathrm{C}$-atom source for further protection. To the right of the shroud is a 4 -way CF 40 cross piece. The top flange of the cross is attached to a rotary shutter. This shutter is situated in between the path of the emitting carbon atoms and the mini UHV gate valve in order to protect the gate valve from carbon buildup during ramping of the current. The gate valve is installed for the purpose of separating the $\mathrm{C}$-atom source from the main chamber when necessary. At the bottom of the cross hangs a micro-ion gauge (Granville-Phillips, 355001-YG). Various sized aperture plates are installed to spatially restrict the carbon atom beam, where more details are found in Sec. II B.

Unlike the HABS and MWAS, the exit of the C-source does not have a nose-shaped quartz tube to help collisionally thermalize newly formed atoms before they impact the ices that are on top of the substrate; $\mathrm{C}$-atoms have a much higher sticking coefficient and would coat the tube effectively with a carbon layer. This means that the impacting $\mathrm{C}$-atoms carry the potential to induce thermal processing of the ice, which would not be representative of interstellar conditions. This is an important issue that has been addressed in more detail in the first science result with this new source; in Qasim et al., ${ }^{39}$ it was demonstrated that, in a $\mathrm{C}+\mathrm{H}+\mathrm{H}_{2} \mathrm{O}$ experimentcombining the HABS and $\mathrm{C}$-atom source-the barrierless formation of $\mathrm{CH}_{4}$ at $10 \mathrm{~K}$ predominantly follows a Langmuir-Hinshelwood mechanism (i.e., diffusing reactants thermalize prior to the reaction on the surface). This suggests the likelihood of thermalization of the involved reactants, but it is not secured as to whether Catoms thermalize with the substrate prior to the reaction, as the formation of $\mathrm{CH}$ in the $\mathrm{C}+\mathrm{H}+\mathrm{H}_{2} \mathrm{O}$ experiment may also proceed via an Eley-Rideal mechanism (i.e., one reactant is not thermalized prior to the reaction). For barrierless reactions, this is not relevant for qualitative studies, as such reactions will proceed regardless of the kinetic energy of the $\mathrm{C}$-atoms. However, for reactions in which a barrier is involved, caution should be taken particularly for quantitative analysis, as the heat of the carbon atoms could open reaction pathways that are not accessible under typical interstellar conditions.

\section{B. Beam size calibration}

The beam size is measured on a gold-decorated substrate that has a width of $24 \mathrm{~mm}$ and length of $38 \mathrm{~mm}$ and is positioned at a horizontal distance of $512 \mathrm{~mm}$ from the tantalum tube. Figure 3 shows the resulting circular carbon atom beam diameter of $21.5 \mathrm{~mm}$ on the gold surface. The beam is narrowed by a combination of stacked oval-like aperture plates (produced by MBE) and circular copper aperture plates (produced in Leiden), as shown in Fig. 2. From left to right, the aperture plates by MBE consist of one pyrolytic graphite (PG) plate with an orifice of $18 \times 6 \mathrm{~mm}^{2}$, five tantalum plates with an orifice of $19 \times 7 \mathrm{~mm}^{2}$, and three tantalum plates with an orifice of $20 \times 12 \mathrm{~mm}^{2}$. The PG plate is placed directly after the source to allow the carbon atom to grow on it without introducing flakes, as thin graphite layers on thin metal parts sometimes create flakes. Multiple plates of the same aperture size are for the purpose of 


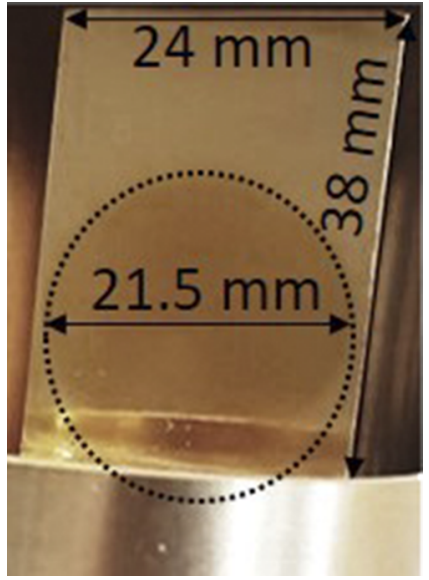

FIG. 3. The darker circle, outlined by a dashed circle, is the carbon deposit that resulted from the atomic beam on the gold surface of the substrate. The entire beam is on the flat surface, and the angle at which the picture is taken makes it appear that the lower part is clipped. A beam diameter of $21.5 \mathrm{~mm}$ is measured on a sample plate that has a size of $38 \times 24 \mathrm{~mm}^{2}$. Note that contrast has been added to the image to visualize the area with impacting $\mathrm{C}$-atoms.

acting as radiation shields. The mean distance between the left-most and the right-most aperture plate is $135 \mathrm{~mm}$. The aperture sizes of the copper plates are $21 \mathrm{~mm}, 20 \mathrm{~mm}, 19 \mathrm{~mm}$, and $18 \mathrm{~mm}$, respectively, where the plate with the smallest aperture is placed closest to the substrate surface. From left to right, the distances between the copper plates are $126 \mathrm{~mm}, 35 \mathrm{~mm}$, and $129 \mathrm{~mm}$. The resulting beam size is optimized in that the majority of the atoms do not go past the sample plate, yet it covers a large fraction of the substrate surface in order to have maximum overlap with the FTIR beam.

\section{Temperature characterization of the graphite-filled tantalum tube}

An approximation for the temperature of the graphite-filled tantalum tube, and consequently of the emitting carbon atoms, is measured by a WRe alloy wire that is largely shielded with $\mathrm{Al}_{2} \mathrm{O}_{3}$ ceramic. A temperature controller (Eurotherm 2408) is primarily used to read out the temperature value. As the thermocouple is placed beneath the tube to protect it from melting, the measured value from the thermocouple is lower than the actual temperature of the heated tube. To know the actual temperature of the graphite-filled tantalum tube, and subsequently the emitting carbon atoms, a pyrometer is used (at MBE) in conjunction with the thermocouple, and the values are shown in Fig. 4. Note that the $\mathrm{C}$-atoms are assumed to be in thermal equilibrium with the tantalum tube, although in reality, their temperatures are lower, as the energy required to release the $\mathrm{C}$-atoms from the tube (physisorption/chemisorption) is not taken into account. Interpolation of the values provides the approximate temperature of the carbon atoms for every thermocouple reading from $728^{\circ} \mathrm{C}$ to $1567^{\circ} \mathrm{C}$. These gasphase temperature values are important for determining the flux of carbon atoms on the sample, as the flux is highly dependent on the filament temperature. Note that the pyrometer values are

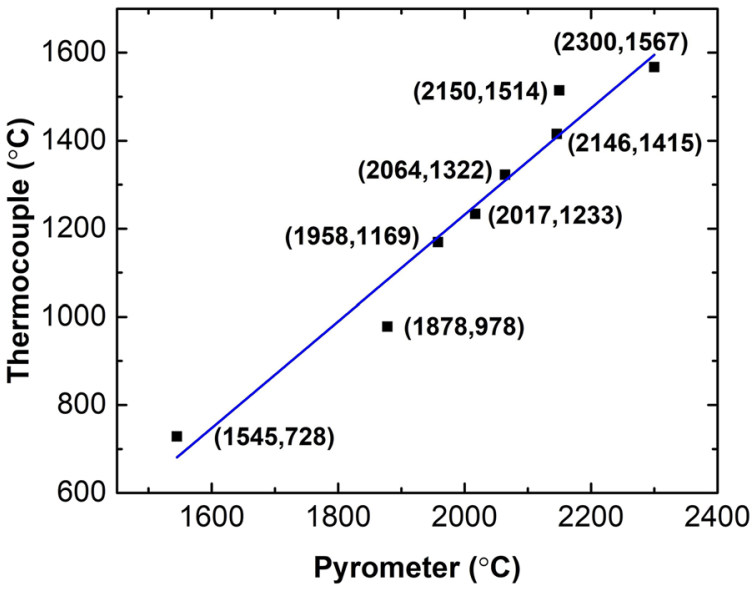

FIG. 4. A linear fit to the thermocouple vs pyrometer temperature values of the tantalum tube. The values from the pyrometer reflect the approximate $\mathrm{C}$-atom temperatures, whereas the values from the thermocouple are lower due to the distance between the thermocouple and the heated tube.

representative of ground state atomic carbon, as the amount of energy required to reach the $\mathrm{C}\left({ }^{1} \mathrm{D}\right)$ excited state is $14665 \mathrm{~K}^{40}$

\section{C-atom flux calibration}

In order to characterize the reaction efficiencies in the ice, it is important to quantify the C-atom flux. In Ioppolo et al., ${ }^{29}$ this was demonstrated for the HABS (H/D) and MWAS (H/D, N, O) fluxes. Here, the calibration procedure for the $\mathrm{C}$-atom source is described through a quantitative analysis of various $\mathrm{C}+{ }^{18} \mathrm{O}_{2}$ co-deposition experiments. RAIRS is used to probe and quantitate the reaction products. A wavelength range of $4000-750 \mathrm{~cm}^{-1}$ with $1 \mathrm{~cm}^{-1} \mathrm{spec}-$ tral resolution is used. In Sec. III, it will be explained that $\mathrm{C}+{ }^{18} \mathrm{O}_{2}$ acts in a barrierless manner to ultimately form $\mathrm{C}^{18} \mathrm{O}+{ }^{18} \mathrm{O} .{ }^{18} \mathrm{O}$ can then barrierlessly react with ${ }^{18} \mathrm{O}_{2}$ to form ${ }^{18} \mathrm{O}_{3} .{ }^{29,41}$ Thus, in a very diluted $\mathrm{C}:{ }^{18} \mathrm{O}_{2}$ matrix of $\sim 1: 500$, the ${ }^{18} \mathrm{O}_{3}$ abundance essentially reflects the $\mathrm{C}$-atom abundance at the substrate. This aimed ratio of 1:500 is determined by estimating the $\mathrm{C}$-atom flux using the $\mathrm{C}$-atom flux values from MBE (application of the inverse-square law), and using the Langmuir approximation $\left(1 \mathrm{~L}=1.3 \times 10^{-6} \mathrm{mbar} \mathrm{s}\right.$ $=1 \times 10^{15}$ molecules $\mathrm{cm}^{-2}$ ) to estimate the ${ }^{18} \mathrm{O}_{2}$ flux. Note that an exact ratio of 1:500 is not critical in these specific experiments, as the main goal is to just create an overabundance of oxygen. Assuming a linear deposition rate, the flux of ${ }^{18} \mathrm{O}_{3}$, and thus atomic $\mathrm{C}$, can be measured. To calculate the ${ }^{18} \mathrm{O}_{3}$ abundance, a modified LambertBeer equation is used, as employed in the previous work. ${ }^{42}$ A setup specific ozone band strength of $4.4 \times 10^{-17} \mathrm{~cm} \mathrm{molecule}^{-1}$ is applied and derived by performing an isothermal consumption experiment of $\mathrm{O}_{3}$ by $\mathrm{H}$-atoms at a deposition temperature of $50 \mathrm{~K}$. The $\mathrm{H}$ atom bombardment of $\mathrm{O}_{3}$ ice at $50 \mathrm{~K}$ proceeds via an Eley-Rideal mechanism to form products, such as $\mathrm{O}_{2}$, which desorbs upon formation. Thus, the rate of $\mathrm{O}_{3}$ consumption by $\mathrm{H}$-atoms is directly proportional to the $\mathrm{H}$-atom flux (i.e., linear) until the surface is only partially covered by $\mathrm{O}_{3}$. At that point, the slope decreases, as the rate of $\mathrm{O}_{3}$ consumption is hindered by the lack of $\mathrm{O}_{3}$ at certain binding sites. Thus, the IR absorbance value of $\mathrm{O}_{3}$ at the 
TABLE I. ${ }^{18} \mathrm{O}_{3}$ (C-atom) flux values at various $\mathrm{C}$-atom temperatures, measured from various $\mathrm{C}+{ }^{18} \mathrm{O}_{2}$ co-deposition experiments. The $\mathrm{C}:{ }^{18} \mathrm{O}_{2}$ ratio is aimed to be $\sim 1: 500$ in the experiments.

\begin{tabular}{lcc}
\hline \hline $\begin{array}{l}\text { Thermocouple } \\
\left({ }^{\circ} \mathrm{C}\right)\end{array}$ & $\begin{array}{c}\text { Deposition time } \\
(\mathrm{s})\end{array}$ & $\begin{array}{c}{ }^{18} \mathrm{O}_{3}(\mathrm{C} \text {-atom) flux } \\
\left(\mathrm{cm}^{-2} \mathrm{~s}^{-1}\right)\end{array}$ \\
\hline 1243 & 600 & $1 \times 10^{11}$ \\
1287 & 600 & $3 \times 10^{11}$ \\
$1312^{\mathrm{a}}$ & 600 & $4 \times 10^{11}$ \\
$1325^{\mathrm{a}}$ & 600 & $7 \times 10^{11}$ \\
1445 & 600 & $3 \times 10^{12}$ \\
1533 & 600 & $7 \times 10^{12}$ \\
\hline \hline
\end{tabular}

${ }^{a}$ Measurement performed with another tantalum tube of the same design.

transition point is considered to represent a monolayer (ML; $1 \mathrm{ML}$ $=1 \times 10^{15}$ molecules $\mathrm{cm}^{-2}$ ) of $\mathrm{O}_{3}$ ice and is used to determine the band strength via the modified Lambert-Beer equation. A similar procedure was described in Ioppolo et al. ${ }^{29}$ to determine band strengths with SURFRESIDE ${ }^{2}$.

The results are summarized in Table I. An exponential curve can be fit to the values in the last column of Table I in order to indirectly achieve $\mathrm{C}$-atom flux values between thermocouple temperatures of $1243^{\circ} \mathrm{C}$ and $1533^{\circ} \mathrm{C}$. The fluxes at the extremes are also measured by MBE for this particular source with a quartz crystal microbalance, and values of $1 \times 10^{11} \mathrm{~cm}^{-2} \mathrm{~s}^{-1}$ and $1 \times 10^{12}$ $\mathrm{cm}^{-2} \mathrm{~s}^{-1}$ are obtained for thermocouple temperatures of $1233^{\circ} \mathrm{C}$ and $1514{ }^{\circ} \mathrm{C}$, respectively. These do not deviate much from the values of $1 \times 10^{11} \mathrm{~cm}^{-2} \mathrm{~s}^{-1}\left(1233^{\circ} \mathrm{C}\right)$ and $5 \times 10^{12} \mathrm{~cm}^{-2} \mathrm{~s}^{-1}\left(1514^{\circ} \mathrm{C}\right)$ obtained with SURFRESIDE ${ }^{3}$. The $5 \times$ deviation in flux at $1514^{\circ} \mathrm{C}$ can be due to a number of factors, such as the use of different vacuum chamber designs/geometries (including different pumping capacities), filament designs, and measurement tools. It is clear that, for the use of this source in experiments for which flux values are needed, it is important to perform a setup specific calibration. Therefore, the method of measuring the ${ }^{18} \mathrm{O}_{3}$ abundance in an oxygenrich $\mathrm{C}+{ }^{18} \mathrm{O}_{2}$ co-deposition experiment to determine the C-flux should be repeated whenever (substantial) vacuum related changes are made. Note that the inverse-square law is applied in order to compare flux values to take properly into account the different distances involved in the two used experimental setups.

\section{EXPERIMENTAL AND COMPUTATIONAL RESULTS}

The first results of carbon atom chemistry with SUKO-A in SURFRESIDE $^{3}$ are presented below. The two experiments are listed in Table II. These experiments are meant to test the performance of the source by conducting simple reactions that also are considered to be of astrochemical relevancy.

Isotopically enhanced gas, such as ${ }^{18} \mathrm{O}_{2}$ (Campro Scientific 97\%), is used to distinguish reaction products from possible contaminants. Other gases used are $\mathrm{H}_{2}$ (Linde 5.0) and $\mathrm{D}_{2}$ (Sigma-Aldrich $99.96 \%$ ). ${ }^{18} \mathrm{O}_{2}$ gas enters the main chamber of SURFRESIDE $^{3}$ through manually operated leak valves from turbomolecularly pumped dosing lines. Experiments proceed in either
TABLE II. Description of the performed experiments. Experiment 1 involves codeposition, and experiment 2 involves pre-deposition. The $\mathrm{C}$-atom fluxes are derived from interpolation of the flux values listed in Table I. The Hertz-Knudsen equation ${ }^{43}$ is used to determine molecular fluxes. $\mathrm{T}_{\mathrm{C} \text {-atoms }}$ refers to the temperature probed by the thermocouple. $(*)$ refers to 10 Langmuirs $(L)$.

\begin{tabular}{lcccccc}
\hline \hline No. & Expt. & $\begin{array}{c}\mathrm{T}_{\text {sample }} \\
(\mathrm{K})\end{array}$ & $\begin{array}{c}\mathrm{T}_{\mathrm{C}-\text { atoms }} \\
\left({ }^{\circ} \mathrm{C}\right)\end{array}$ & $\begin{array}{c}\text { Flux } \mathrm{C}-\text { atoms } \\
\left(\mathrm{cm}^{-2} \mathrm{~s}^{-1}\right)\end{array}$ & $\begin{array}{c}\mathrm{Flux}^{18} \mathrm{O}_{3} \\
\left(\mathrm{~cm}^{-2} \mathrm{~s}^{-1}\right)\end{array}$ & $\begin{array}{c}\text { Time } \\
(\mathrm{s})\end{array}$ \\
\hline 1 & $\mathrm{C}+{ }^{18} \mathrm{O}_{2}$ & 10 & 1315 & $4 \times 10^{11}$ & $8 \times 10^{13}$ & 3000 \\
2 & $\mathrm{C}+{ }^{18} \mathrm{O}_{2}$ & 10 & 1315 & $4 \times 10^{11}$ & $*$ & 3000 \\
\hline \hline
\end{tabular}

a pre-deposition or a co-deposition manner. In the pre-deposition experiment, molecules are first deposited, followed by C-atom bombardment. In the co-deposition experiments, all species are deposited simultaneously. A major advantage of co-deposition is that product abundance is enhanced due to the constant replenishment of reactants in the ice upper layer. It is also more representative of interstellar processes. ${ }^{32}$ Pre-deposition, on the other hand, allows monitoring of the kinetics of formation and consumption of products and reactants, as the initial abundance is known. This method is also preferred when layered ices have to be studied. More detailed information on the application of these two deposition methods can be found in Ioppolo, Öberg, and Linnartz. ${ }^{44}$

Relative molecular abundances are determined by using a modified Lambert-Beer equation, as done previously with the ozone abundance. The infrared band strength of $\mathrm{C}^{18} \mathrm{O}\left(2086 \mathrm{~cm}^{-1}\right)$ used is $5.2 \times 10^{-17} \mathrm{~cm} \mathrm{molecule}{ }^{-1}$. For $\mathrm{C}^{18} \mathrm{O}_{2}\left(2308 \mathrm{~cm}^{-1}\right)$, a band strength of $4.2 \times 10^{-16} \mathrm{~cm}$ molecule ${ }^{-1}$ is used. This value is obtained

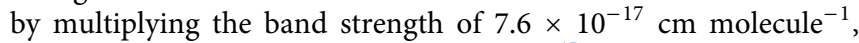
which is from the work by Bouilloud et al., ${ }^{45}$ by a transmission-toRAIR setup specific proportionality factor of 5.5 , in which the band strength of CO from Chuang et al. ${ }^{42}$ is used.

Figure 5 features the IR signatures of the reaction products of the $\mathrm{C}+{ }^{18} \mathrm{O}_{2}$ co-deposition experiment. Such products are $\mathrm{C}^{18} \mathrm{O}_{2}$, $\mathrm{C}^{18} \mathrm{O}$, and ${ }^{18} \mathrm{O}_{3}$. Particularly for the formation of $\mathrm{C}^{18} \mathrm{O}_{2}$ and $\mathrm{C}^{18} \mathrm{O}$, there may be more than one pathway to forming these species. Thus, for a more complete understanding of the $\mathrm{C}+\mathrm{O}_{2}$ reaction network, relevant computationally derived activation and reaction energies are needed and are shown in Table III. Connecting these energy values to the experimental results can delineate the product formation pathways.

All the density functional theory (DFT) calculations are performed in a gas-phase model, which can be expected to cover the main effects, ${ }^{46}$ using Turbomole, ${ }^{47}$ accessed via ChemShell. ${ }^{48,49}$ The unrestricted M06-2X functional $^{50}$ is used in conjunction with the def2-TZVP ${ }^{51}$ basis set. The geometry optimizations are carried out at the same level of theory using the DL-Find ${ }^{52}$ optimizer interfaced via ChemShell. The connecting first-order saddle points (transition states) are obtained using the dimer method. ${ }^{53,54}$ Numerical Hessians in DL-Find are used to characterize the optimized geometries as local minima or transition states. Reported energies include harmonic vibrational zero point energies. Intrinsic reaction coordinate (IRC) ${ }^{55,56}$ calculations are performed to confirm the connections between the transition states and the local minima. Benchmark calculations are carried out using coupled-cluster level 


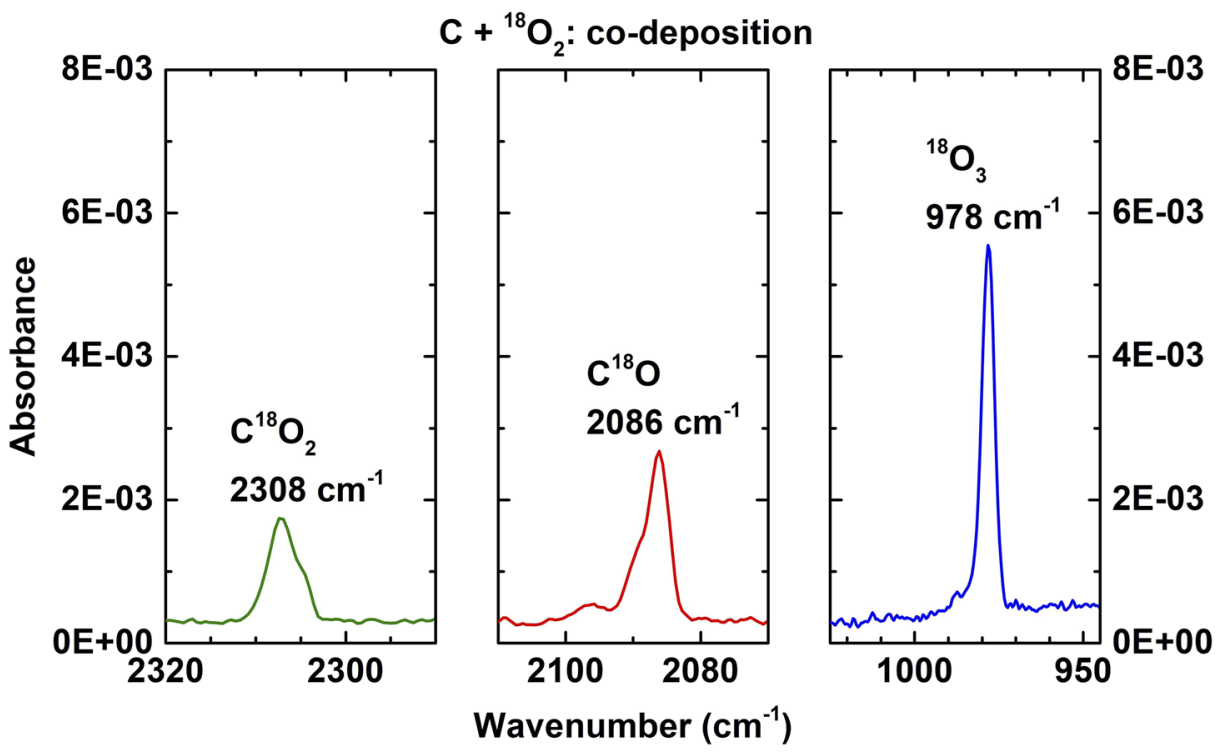

FIG. 5. A RAIR spectrum acquired after co-deposition of atomic $\mathrm{C}$ and ${ }^{18} \mathrm{O}_{2}$ on a $10 \mathrm{~K}$ surface (expt. 1). The features of the reaction products, $\mathrm{C}^{18} \mathrm{O}_{2}$ (left), $\mathrm{C}^{18} \mathrm{O}$ (middle), and ${ }^{18} \mathrm{O}_{3}$ (right), are highlighted. $A C^{18} \mathrm{O}: \mathrm{C}^{18} \mathrm{O}_{2}$ abundance ratio of $12: 1$ is measured.
$\mathrm{UCCSD}(\mathrm{T})-\mathrm{F} 12,^{57,58}$ with a restricted Hartree-Fock reference and cc-PVTZ-F12 ${ }^{59}$ basis set in Molpro. ${ }^{60}$

As demonstrated from the computational work, the reaction of $\mathrm{C}+\mathrm{O}_{2}$ barrierlessly leads to the intermediate, linear $\mathrm{C}-\mathrm{O}-\mathrm{O}$. This process is exothermic by $410 \mathrm{~kJ} / \mathrm{mol}$ in comparison with $\mathrm{C}$ $+\mathrm{O}_{2} \rightarrow \mathrm{CO}+\mathrm{O}$, which has a reaction energy of $-372 \mathrm{~kJ} / \mathrm{mol}$. In this context, it is noteworthy that both $\mathrm{C}$ and $\mathrm{O}_{2}$ are in their triplet ground states. As they combine to a singlet state, applying spin conservation results in the generated $\mathrm{O}$-atom to also be in its excited singlet state. Thus, if energy is not dissipated into the ice, the overall process of $\mathrm{CO}$ formation is thought to be as fast as an actual barrierless reaction [decay of linear $\mathrm{C}-\mathrm{O}-\mathrm{O}$ to $\left.\mathrm{CO}+\mathrm{O}\left({ }^{1} \mathrm{D}\right)\right]$. $\mathrm{CO}$ can also be formed by the barrierless reaction of $\mathrm{C}+\mathrm{O}_{3} \rightarrow \mathrm{CO}$ $+\mathrm{O}_{2}$, as listed in Table III. In Fig. $6,{ }^{18} \mathrm{O}_{3}$ is formed by the barrierless reaction of ${ }^{18} \mathrm{O}_{2}+{ }^{18} \mathrm{O}$, as shown by the increasing signal

TABLE III. Activation and reaction energies for $\mathrm{C}+\mathrm{O}_{2}, \mathrm{CO}+\mathrm{O}\left({ }^{3} \mathrm{P}\right), \mathrm{C}+\mathrm{O}_{3}$, $\mathrm{C}+\mathrm{CO}_{2}$, and $\mathrm{C}_{2} \mathrm{O}+\mathrm{CO}$ calculated at the M06-2X/def2-TZVP level of theory. Additionally, a benchmark is performed with the CCSD(T)-F12/VTZ-F12 functional.

\begin{tabular}{llcc}
\hline \hline Reaction & Product(s) & $\begin{array}{c}\text { Activation energy } \\
(\mathrm{kJ} / \mathrm{mol})\end{array}$ & $\begin{array}{c}\text { Reaction energy } \\
(\mathrm{kJ} / \mathrm{mol})\end{array}$ \\
\hline $\mathrm{C}+\mathrm{O}_{2}{ }^{\mathrm{a}}$ & $\mathrm{CO}+\mathrm{O}\left({ }^{1} \mathrm{D}\right)$ & 0 & -372 \\
$\mathrm{CO}+\mathrm{O}\left({ }^{3} \mathrm{P}\right)$ & $\mathrm{CO}_{2}{ }^{\mathrm{c}}$ & $\ldots$ & -1106 \\
$\mathrm{CO}+\mathrm{O}_{3}$ & $\mathrm{CO}+\mathrm{O}_{2}$ & 25 & -527 \\
$\mathrm{C}+\mathrm{CO}_{2}$ & $\mathrm{CO}+\mathrm{CO}$ & 0 & -981 \\
$\mathrm{C}_{2} \mathrm{O}+\mathrm{CO}$ & $\mathrm{C}_{3} \mathrm{O}_{2}$ & 29 & -540 \\
\hline \hline
\end{tabular}

${ }^{\mathrm{a}}$ Formation of the intermediate, linear $\mathrm{C}-\mathrm{O}-\mathrm{O}$, is further discussed in the main text.

${ }^{b}$ Barrierless if energy from the formation of the linear $\mathrm{C}-\mathrm{O}-\mathrm{O}$ intermediate goes into the reaction (see the main text for more details).

${ }^{\mathrm{c}}$ Tentative (see the main text for more details). of ${ }^{18} \mathrm{O}_{3}$. Likely when ${ }^{18} \mathrm{O}_{2}$ becomes limited, ${ }^{18} \mathrm{O}_{3}$ starts to be consumed by $\mathrm{C}$, as shown by the decreasing signal of ${ }^{18} \mathrm{O}_{3}$. Yet in the co-deposition experiment, it is unlikely that $\mathrm{C}^{18} \mathrm{O}$ is formed from $\mathrm{C}$ $+{ }^{18} \mathrm{O}_{3}$, since the matrix of ${ }^{18} \mathrm{O}_{2}$ hinders the reaction between $\mathrm{C}$ and formed ${ }^{18} \mathrm{O}_{3}$.

If energy is dissipated into the ice, which is probable to occur as energy dissipation appears to occur within picoseconds, ${ }^{31,61,62}$ linear $\mathrm{C}-\mathrm{O}-\mathrm{O}$ can decay to $\mathrm{CO}_{2}$. However, it should be noted that a continuous reaction path to $\mathrm{CO}_{2}$ is not found in the present computational simulations due to strong multireference character in the wave function, which is why $\mathrm{CO}_{2}$ formation from

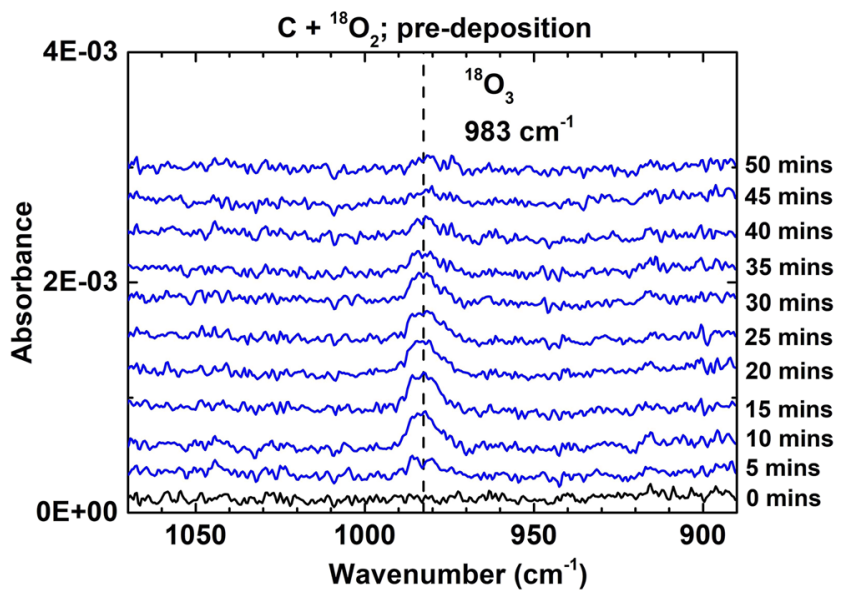

FIG. 6. RAIR spectra acquired after pre-deposition of atomic $\mathrm{C}$ and ${ }^{18} \mathrm{O}_{2}$ on a $10 \mathrm{~K}$ surface (expt. 2). $10 \mathrm{~L}$ of ${ }^{18} \mathrm{O}_{2}$ is first deposited, followed by carbonation for $50 \mathrm{~min}$. The increase and subsequent decrease in the ${ }^{18} \mathrm{O}_{3}$ band are highlighted. RAIR spectra are offset for clarity. 
$\mathrm{C}+\mathrm{O}_{2}$ is noted as tentative in Table III. $\mathrm{CO}_{2}$ can also be formed by $\mathrm{CO}+\mathrm{O}\left({ }^{3} \mathrm{P}\right)$, albeit having a high barrier of $25 \mathrm{~kJ} / \mathrm{mol}$, if $\mathrm{O}\left({ }^{3} \mathrm{P}\right)$ is in fact formed. $\mathrm{CO}+\mathrm{O}\left({ }^{1} \mathrm{D}\right)$ is barrierless to $\mathrm{CO}_{2}$ formation. The abundance ratio of $12: 1$ for $\mathrm{C}^{18} \mathrm{O}: \mathrm{C}^{18} \mathrm{O}_{2}$ measured in experiment 1 shows that $\mathrm{C}^{18} \mathrm{O}$ is the more favored product, and thus, $\mathrm{C}^{18} \mathrm{O}_{2}$ formation is relatively inefficient under our experimental conditions.

The results of the $\mathrm{C}+{ }^{18} \mathrm{O}_{2}$ experiments demonstrate that the $\mathrm{C}$-atom source performs well under our astrochemically relevant experimental conditions to study solid-state reactions. Particularly, the available $\mathrm{C}$-atom flux is sufficient to yield high quality spectra, which allows for qualitative and quantitative analysis of the involved chemical pathways. Other recent results, describing the solid-state formation of methane from $\mathrm{C}+\mathrm{H}$ using the system described here, are available from Ref. 39.

\section{ASTROCHEMICAL IMPLICATIONS}

The new experiments described here are needed to understand how carbonaceous species, and particularly COMs, can be formed by carbon atom chemistry in the early phase of molecular cloud evolution. Such chemistry is expected to be most applicable to the $\mathrm{H}_{2} \mathrm{O}$-rich ice phase, which has a visual extinction $\left(A_{V}\right)$ of $1.5<A_{V}<3 .^{33}$ At such cloud depths, atomic carbon is present and becomes increasingly locked up in gas-phase $\mathrm{CO}$ at greater extinctions $\left(>3 A_{V}\right){ }^{23,33}$ This carbon then has the chance to react with atomic hydrogen on grain surfaces, for example, to form simple species such as $\mathrm{CH}_{4} \cdot{ }^{64}$ The intermediate hydrocarbon radicals, $\mathrm{CH}_{x}$, may also have the opportunity to react with other species in the $\mathrm{H}_{2} \mathrm{O}$-rich ice phase to form COMs. It should be noted that deeper into the cloud when $\mathrm{CO}$ freezes out, $\mathrm{C}$ can also be formed by the dissociation of $\mathrm{CO}$ by cosmic-ray-induced processes. 1,18

The reaction of $\mathrm{C}+\mathrm{O}_{2}$ in interstellar molecular clouds may occur, as it is demonstrated to be a barrierless reaction, but not expected to be relatively frequent. Although interstellar $\mathrm{O}_{2}$ ice has not been detected, $\mathrm{O}_{2}$ has been detected in icy bodies, such as in the coma of comet 67P/Churyumov-Gerasimenko, and is thought to have primordial origin. ${ }^{65,66}$ As found in Taquet et al. ${ }^{66}$ the distributions of the $\mathrm{O}_{2}$ ice abundance at $A_{V}=2,4,6,8$, and 10 are similar between the $A_{V}$ levels. Thus, the astrochemical timescales of relatively abundant $\mathrm{C}$ and $\mathrm{O}_{2}$ should overlap. However, atoms such as $\mathrm{H}$ and $\mathrm{O}$ also barrierlessly react with $\mathrm{O}_{2}$ and are at least an order of magnitude higher in abundance than $\mathrm{C}$ at the same timescales. ${ }^{24,25,66}$ Therefore, the reaction of $\mathrm{C}$ with $\mathrm{O}_{2}$ in the translucent and dense phases of interstellar clouds is assumed to be minor for $\mathrm{O}_{2}$ consumption. Nonetheless, the experimental and theoretical work presented here shows that atomic carbon and molecular oxygen can readily react if they would neighbor each other on a dust grain. The $\mathrm{C}+\mathrm{O}_{2}$ products, $\mathrm{CO}$, and possibly $\mathrm{O}\left({ }^{3} \mathrm{P}\right)$ and $\mathrm{CO}_{2}$, are unlikely to further react with each other in the laboratory or in the interstellar medium, as such reactions are associated with high activation barriers, as found in Table III. This includes $\mathrm{CO}+\mathrm{O}\left({ }^{3} \mathrm{P}\right) \rightarrow \mathrm{CO}_{2}$ $(25 \mathrm{~kJ} / \mathrm{mol}), \mathrm{C}+\mathrm{CO}_{2} \rightarrow \mathrm{CO}+\mathrm{CO}(29 \mathrm{~kJ} / \mathrm{mol})$, and $\mathrm{C}_{2} \mathrm{O}+\mathrm{CO} \rightarrow$ $\mathrm{C}_{3} \mathrm{O}_{2}(30 \mathrm{~kJ} / \mathrm{mol})$. However, the formation of $\mathrm{O}\left({ }^{1} \mathrm{D}\right)$ from $\mathrm{C}+\mathrm{O}_{2}$ may explain why $\mathrm{CO}_{2}$ is formed starting from a "non-energetic" reaction, in which "non-energetic" refers to a radical-induced process that does not include an external energy source such as UV, cosmic rays, electrons, and/or simple heating of the ice. The reaction of $\mathrm{C}+\mathrm{O}_{3}$ is barrierless and thus may also occur in space. However, it is expected to be relatively infrequent for the same reasons as those for the $\mathrm{C}+\mathrm{O}_{2}$ reaction.

The general relevance for the astrochemical community of using a C-atom source in a setup fully optimized to study atom addition/abstraction reactions in interstellar ice analogs is that it extends on reaction networks proposed before (e.g., Ref. 16) but has not been investigated in the laboratory yet. It is expected that experimental investigations of solid-state C-atom chemistry will provide some of the missing fingerprints for how different carbon-bearing species are formed in interstellar ices. To date, the formation of solid-state COMs and other carbon-bearing molecules under interstellar relevant conditions is largely investigated through the combination of molecular radicals (e.g., $\mathrm{HCO}, \mathrm{C}_{2} \mathrm{H}_{3}, \mathrm{CH}_{3} \mathrm{O}$ ), as this way to build the carbon backbone has been experimentally realized for some time. Although it is an important and relevant way to form solid-state carbon-containing species, it is likely not the explanation for the formation of all such species. This is in part due to the presence of atomic carbon in translucent and dense clouds. As atomic $\mathrm{C}$ is highly reactive, it may feasibly evolve into $\mathrm{C}_{x} \mathrm{H}_{y}$ structures. These structures can then react with other radicals to form alcohols and aldehydes, as shown in Qasim et al. ${ }^{31}$ and Qasim et al. ${ }^{67}$ Alcohols, aldehydes, and other functional groups may also be formed starting from $\mathrm{HCO}$ $+\mathrm{C}^{1,16}$ and/or $\mathrm{CCO}+\mathrm{H}$. Thus, this work will help understand the relative significance of radical recombination and direct $\mathrm{C}$-atom addition reactions in various interstellar molecular cloud environments. For this, astrochemical modeling will be needed, taking into account the available $\mathrm{C}$-atom abundances in different astronomical environments. With the options SURFRESIDE ${ }^{3}$ offers, it will become possible to provide information on possible reaction networks and reaction efficiencies and on full dependence of astronomically relevant temperatures.

With the expected launch of the JWST in the near future, ice observations should become more prevalent, which also increases the necessity of laboratory $\mathrm{C}$-atom reactions. To date, telescopes have suffered from telluric contamination (ground-based) and lacked the sensitivity to probe ice molecules more complex than methanol. The JWST will provide telluric free data, sensitivity and/or spectral resolution in the mid-IR that is orders of magnitude higher than that encountered with previous telescopes such as the Infrared Space Observatory (ISO) or Spitzer, ${ }^{68}$ and perform ice mapping. These traits alone make the JWST a desired facility for ice observations, and preparations to search for COMs have already been carried out in the laboratory. ${ }^{69}$ As possible COMs from $\mathrm{C}$-atom chemistry are expected to be formed primarily in the $\mathrm{H}_{2} \mathrm{O}$ rich ice phase, and not in the CO-rich ice phase, C-atom chemistry experiments may provide insight into the origin of the COMs that will be targeted by the JWST. For example, a COM that is effectively formed by C-atom chemistry, but not by other studied pathways, suggests that the detected COM is formed in the polar phase of the cloud. Currently, not even methanol has been directly and exclusively detected in this phase in quiescent clouds (see Fig. 7 of Boogert, Gerakines, and Whittet ${ }^{33}$ ), and this is a consequence of the relatively low amount of ice at such low extinctions $\left(A_{V}<3\right)$. Thus, this is the ideal time period to investigate $\mathrm{C}$-atom chemistry, as the JWST may have the sensitivity to detect COMs directly in the polar phase that are formed starting from atomic C. 


\section{CONCLUSIONS}

For the first time, an atomic carbon source capable of producing fluxes in the low $10^{11}$-high $10^{12} \mathrm{~cm}^{-2} \mathrm{~s}^{-1}$ range is incorporated into a modified setup that is designed to study the "non-energetic" chemical processes of interstellar ice analogs. The source comes with new advantages: (1) An alternative way to investigate carbon chemistry in space along a principle that has not been studied so far. (2) A reliable and straightforward method to calibrate the Catom flux in SURFRESIDE ${ }^{3}$ is available. The flux is adequate to probe $\mathrm{C}$-atom chemistry in SURFRESIDE ${ }^{3}$, such as the reaction of $\mathrm{C}+{ }^{18} \mathrm{O}_{2}$. The experimental results and computationally derived activation barriers suggest that atomic carbon can react with $\mathrm{O}_{2}$ and $\mathrm{O}_{3}$ ices in interstellar molecular clouds, although more abundant species will effectively compete with C. (3) The beam size can be directly measured, which makes it achievable to operate the source without inducing hazardous carbon pollution into the vacuum system. The use of the source also comes with challenges to keep in mind: (1) The production of carbon layers on the sample surface is unavoidable in an experiment (i.e., all experiments take place on a carbonaceous surface). However, the layers observed have a negligible effect on the RAIR intensity. (2) The flux is highly dependent on the filament temperature, and the filament temperature steadily changes within an experiment partially due to the ongoing release of $\mathrm{C}$-atoms. Thus, the longer the experiment, the greater the deviation of the flux between the start and the end of the experiment. (3) On average, the lifetime of a tube is around $14 \mathrm{~h}$ at thermocouple temperatures of around $1300{ }^{\circ} \mathrm{C}$. This complicates experiments due to the necessary replacement of the tube, which requires breaking of the vacuum of the $\mathrm{C}$-atom chamber. Moreover, the commercial carbon tubes are relatively expensive. (4) The extent of thermalization of the $\mathrm{C}$-atoms to the temperature of the substrate is not fully secured yet, and therefore, $\mathrm{C}$-atom reactions involving activation barriers require caution, particularly if quantitative analysis is performed. Future studies will focus on developing a method to measure the extent to which $\mathrm{C}$-atoms thermally equilibrate with the sample.

With the positive performance of the modified setup, it is now possible to test what type of COMs can be formed by C-atom chemistry, primarily in $\mathrm{H}_{2} \mathrm{O}$-rich ice, as these types of COMs are thought to be mixed primarily with $\mathrm{H}_{2} \mathrm{O}$ (and also some $\mathrm{CO}$ ). Such investigations overlap well with the expected launch of the JWST, which will have a sensitivity in the mid-IR that can possibly pick up signatures of COMs formed in low extinction $\left(A_{V} \sim 2-3\right)$ environments directly-something that has yet to be conducted with current observational facilities.

\section{ACKNOWLEDGMENTS}

This research benefited from the joint financial support by the Dutch Astrochemistry Network II (DANII) and NOVA (the Netherlands Research School for Astronomy). Further support includes a VICI grant of NWO (the Netherlands Organization for Scientific Research) and A-ERC Grant No. 291141 (CHEMPLAN). D.Q. acknowledges Andreas Jendrzey for many helpful discussions and Vianney Taquet for insightful feedback. The Leiden team specifically thanks Jiao He for on spot support, regular discussions and critical feedback. T.B. and J.K. acknowledge funding by the European Union's Horizon 2020 research and innovation program (Grant
Agreement No. 646717, TUNNELCHEM). S.I. acknowledges the Royal Society for financial support and the Holland Research School of Molecular Chemistry (HRSMC) for a travel grant.

\section{REFERENCES}

${ }^{1}$ E. Herbst and E. F. van Dishoeck, "Complex organic interstellar molecules," Annu. Rev. Astron. Astrophys. 47, 427-480 (2009)

${ }^{2}$ T. Soma, N. Sakai, Y. Watanabe, and S. Yamamoto, "Complex organic molecules in Taurus Molecular Cloud-1,” Astrophys. J. 854, 116 (2018).

${ }^{3}$ A. Bacmann, A. Faure, and J. Berteaud, "Cold and yet complex: Detection of ethylene oxide in a prestellar core," ACS Earth Space Chem. 3, 1000-1013 (2019).

${ }^{4}$ A. Belloche, H. S. Müller, K. M. Menten, P. Schilke, and C. Comito, "Complex organic molecules in the interstellar medium: IRAM $30 \mathrm{~m}$ line survey of Sagittarius B2(N) and (M)," Astron. Astrophys. 559, A47 (2013).

${ }^{\mathbf{5}}$ A. Belloche, H. Müller, R. Garrod, and K. Menten, "Exploring molecular complexity with ALMA (EMoCA): Deuterated complex organic molecules in Sagittarius B2(N2)," Astron. Astrophys. 587, A91 (2016).

${ }^{6}$ J. M. Lykke, A. Coutens, J. K. Jørgensen, M. H. D. van der Wiel, R. T. Garrod, H. Müller, P. Bjerkeli, T. Bourke, H. Calcutt, M. Drozdovskaya, and C. Favre, "The ALMA-PILS survey: First detections of ethylene oxide, acetone and propanal toward the low-mass protostar IRAS 16293-2422," Astron. Astrophys. 597, A53 (2017).

${ }^{7}$ R. T. Garrod and E. Herbst, "Formation of methyl formate and other organic species in the warm-up phase of hot molecular cores," Astron. Astrophys. 457, 927-936 (2006)

${ }^{8}$ A. I. Vasyunin, P. Caselli, F. Dulieu, and I. Jiménez-Serra, "Formation of complex molecules in prestellar cores: A multilayer approach," Astrophys. J. 842, 33 (2017).

${ }^{9}$ K.-J. Chuang, G. Fedoseev, S. Ioppolo, E. F. van Dishoeck, and H. Linnartz, "Hatom addition and abstraction reactions in mixed $\mathrm{CO}, \mathrm{H}_{2} \mathrm{CO}$ and $\mathrm{CH}_{3} \mathrm{OH}$ ices-an extended view on complex organic molecule formation," Mon. Not. R. Astron. Soc. 455, 1702-1712 (2016).

${ }^{10}$ T. Butscher, F. Duvernay, A. Rimola, M. Segado-Centellas, and T. Chiavassa, "Radical recombination in interstellar ices, a not so simple mechanism," Phys. Chem. Chem. Phys. 19, 2857-2866 (2017).

${ }^{11}$ G. Fedoseev, K.-J. Chuang, S. Ioppolo, D. Qasim, E. F. van Dishoeck, and H. Linnartz, "Formation of glycerol through hydrogenation of CO ice under prestellar core conditions," Astrophys. J. 842, 52 (2017).

${ }^{12}$ S. Álvarez-Barcia, P. Russ, J. Kästner, and T. Lamberts, "Hydrogen transfer reactions of interstellar complex organic molecules," Mon. Not. R. Astron. Soc. 479, 2007-2015 (2018).

${ }^{13}$ T. Lamberts, M. N. Markmeyer, F. J. Kolb, and J. Kästner, "Formation of acetaldehyde on CO-rich ices," ACS Earth Space Chem. 3, 958-963 (2019).

${ }^{14}$ A. Tielens and S. Charnley, "Circumstellar and interstellar synthesis of organic molecules," in Planetary and Interstellar Processes Relevant to the Origins of Life (Springer, 1997), pp. 23-51.

${ }^{15}$ S. Charnley, "Interstellar organic chemistry," in The Bridge between the Big Bang and Biology: Stars, Planetary Systems, Atmospheres, Volcanoes: Their Link to Life, edited by F. Giovannelli (SAO/NASA Astrophysics Data System, 2001), pp. 139-149.

${ }^{16}$ S. Charnley and S. Rodgers, "Pathways to molecular complexity," in Astrochemistry: Recent Successes and Current Challenges, IAU Colloquium 231, edited by D. Lis, G. Blake, and E. Herbst (Cambridge University Press, 2005), Vol. 1, pp. 237-246.

${ }^{17}$ S. Charnley and S. Rodgers, "Theoretical models of complex molecule formation on dust," in Bioastronomy 2007: Molecules, Microbes and Extraterrestrial Life, edited by K. J. Meech, J. V. Keane, M. J. Mumma, J. L. Siefert, and D. J. Werthimer (Astronomical Society of the Pacific, 2009), Vol. 420, p. 29.

${ }^{18}$ M. Requena-Torres, J. Martín-Pintado, S. Martín, and M. Morris, “The galactic center: The largest oxygen-bearing organic molecule repository," Astrophys. J. 672, 352-360 (2008).

${ }^{19}$ M. Simončič, D. Semenov, S. Krasnokutski, T. Henning, and C. Jäger, "Sensitivity of gas-grain chemical models to surface reaction barriers: Effect 
from a key carbon-insertion reaction, $\mathrm{C}+\mathrm{H}_{2} \rightarrow \mathrm{CH}_{2}$," Astron. Astrophys, (in press).

${ }^{20} \mathrm{~T}$. Phillips and P. Huggins, "Abundance of atomic carbon (CI) in dense interstellar clouds,” Astrophys. J. 251, 533-540 (1981).

${ }^{21}$ E. F. Van Dishoeck, J. H. Black et al., "The photodissociation and chemistry of interstellar CO," Astrophys. J. 334, 771-802 (1988).

${ }^{22}$ E. Herbst, "Chemistry of star-forming regions," J. Phys. Chem. A 109, 40174029 (2005)

${ }^{23}$ E. F. van Dishoeck, "The chemistry of diffuse and dark interstellar clouds," in The Molecular Astrophysics of Stars and Galaxies, edited by T. Hartquist and D. Williams (Clarendon Press, Oxford, 1998), p. 53.

${ }^{24}$ D. Hollenbach, M. J. Kaufman, E. A. Bergin, and G. J. Melnick, "Water, $\mathrm{O}_{2}$, and ice in molecular clouds," Astrophys. J. 690, 1497 (2008).

${ }^{25} \mathrm{~V}$. Taquet, S. B. Charnley, and O. Sipilä, "Multilayer formation and evaporation of deuterated ices in prestellar and protostellar cores," Astrophys. J. 791, 1 (2014).

${ }^{26}$ S. Krasnokutski, M. Kuhn, M. Renzler, C. Jäger, T. Henning, and P. Scheier, "Ultra-low-temperature reactions of carbon atoms with hydrogen molecules," Astrophys. J. 818, L31 (2016).

${ }^{27}$ T. K. Henning and S. A. Krasnokutski, "Experimental characterization of the energetics of low-temperature surface reactions," Nat. Astron. 3, 568 (2019).

${ }^{28}$ S. Krasnokutski, M. Goulart, E. Gordon, A. Ritsch, C. Jäger, M. Rastogi, W. Salvenmoser, T. Henning, and P. Scheier, "Low-temperature condensation of carbon," Astrophys. J. 847, 89 (2017).

${ }^{29}$ S. Ioppolo, G. Fedoseev, T. Lamberts, C. Romanzin, and H. Linnartz, "SURFRESIDE": An ultrahigh vacuum system for the investigation of surface reaction routes of interstellar interest," Rev. Sci. Instrum. 84, 073112 (2013).

${ }^{30}$ S. Ioppolo, H. Cuppen, C. Romanzin, E. F. van Dishoeck, and H. Linnartz, "Water formation at low temperatures by surface $\mathrm{O}_{2}$ hydrogenation I: Characterization of ice penetration," Phys. Chem. Chem. Phys. 12, 12065-12076 (2010).

${ }^{31}$ D. Qasim, G. Fedoseev, T. Lamberts, K.-J. Chuang, J. He, S. Ioppolo, J. Kästner, and $\mathrm{H}$. Linnartz, "Alcohols on the rocks: Solid-state formation in a $\mathrm{H}_{3} \mathrm{CC} \equiv \mathrm{CH}$ + OH cocktail under dark cloud conditions," ACS Earth Space Chem. 3, 986-999 (2019).

${ }^{32} \mathrm{H}$. Linnartz, S. Ioppolo, and G. Fedoseev, "Atom addition reactions in interstellar ice analogues," Int. Rev. Phys. Chem. 34, 205-237 (2015).

${ }^{33}$ A. Boogert, P. A. Gerakines, and D. C. Whittet, "Observations of the icy universe," Annu. Rev. Astron. Astrophys. 53, 541-581 (2015).

${ }^{34}$ S. Krasnokutski and F. Huisken, "A simple and clean source of low-energy atomic carbon," Appl. Phys. Lett. 105, 113506 (2014).

${ }^{35} \mathrm{~J}$. Albar, A. Summerfield, T. S. Cheng, A. Davies, E. Smith, A. N. Khlobystov, C. Mellor, T. Taniguchi, K. Watanabe, C. Foxon et al., "An atomic carbon source for high temperature molecular beam epitaxy of graphene," Sci. Rep. 7, 6598 (2017).

${ }^{36} \mathrm{~K}$. Tschersich and V. Von Bonin, "Formation of an atomic hydrogen beam by a hot capillary," J. Appl. Phys. 84, 4065-4070 (1998).

${ }^{37} \mathrm{~K}$. Tschersich, "Intensity of a source of atomic hydrogen based on a hot capillary,” J. Appl. Phys. 87, 2565-2573 (2000).

${ }^{38} \mathrm{~K}$. Tschersich, J. Fleischhauer, and H. Schuler, "Design and characterization of a thermal hydrogen atom source," J. Appl. Phys. 104, 034908 (2008).

${ }^{39}$ D. Qasim, G. Fedoseev, K. J. Chuang, J. He, S. Ioppolo, E. F. van Dishoeck, and H. Linnartz, "An experimental study of the surface formation of methane in interstellar molecular clouds," Nature Astron. (published online 2020).

${ }^{40}$ A. Kramida, Yu Ralchenko, J. Reader, and NIST ASD Team, NIST Atomic Spectra Database (ver. 5.6.1), National Institute of Standards and Technology, Gaithersburg, MD, 2018, available: https://physics.nist.gov/asd; accessed: September 13, 2019.

${ }^{41} \mathrm{C}$. Lin and $\mathrm{M}$. Leu, "Temperature and third-body dependence of the rate constant for the reaction $\mathrm{O}+\mathrm{O}_{2}+\mathrm{M} \rightarrow \mathrm{O}_{3}+\mathrm{M}$," Int. J. Chem. Kinet. 14, 417-434 (1982).

${ }^{42}$ K.-J. Chuang, G. Fedoseev, D. Qasim, S. Ioppolo, E. F. van Dishoeck, and H. Linnartz, "Reactive desorption of CO hydrogenation products under cold pre-stellar core conditions," Astrophys. J. 853, 102 (2018).
${ }^{43}$ K. W. Kolasinski, Surface Science: Foundations of Catalysis and Nanoscience (John Wiley \& Sons, West Chester, PA, 2012).

${ }^{44}$ S. Ioppolo, K. Öberg, and H. Linnartz, "Solid-state pathways toward molecular complexity in space," in Laboratory Astrochemistry: From Molecules through Nanoparticles to Grains, edited by S. Schlemmer, T. Giesen, and H. Mutschke (John Wiley \& Sons, 2014), Chap. 5.4, pp. 289-309.

${ }^{45}$ M. Bouilloud, N. Fray, Y. Bénilan, H. Cottin, M.-C. Gazeau, and A. Jolly, "Bibliographic review and new measurements of the infrared band strengths of pure molecules at $25 \mathrm{~K}: \mathrm{H}_{2} \mathrm{O}, \mathrm{CO}_{2}, \mathrm{CO}, \mathrm{CH}_{4}, \mathrm{NH}_{3}, \mathrm{CH}_{3} \mathrm{OH}, \mathrm{HCOOH}$ and $\mathrm{H}_{2} \mathrm{CO}$," Mon. Not. R. Astron. Soc. 451, 2145-2160 (2015).

${ }^{46} \mathrm{~J}$. Meisner, T. Lamberts, and J. Kästner, "Atom tunneling in the water formation reaction $\mathrm{H}_{2}+\mathrm{OH} \rightarrow \mathrm{H}_{2} \mathrm{O}+\mathrm{H}$ on an ice surface," ACS Earth Space Chem. 1, 399410 (2017)

${ }^{47}$ TURBOMOLE, V7.0.01, a development of University of Karlsruhe and Forschungszentrum Karlsruhe GmbH, 1989-2007, TURBOMOLE GmbH, 2007, available at http://www.turbomole.com, 2018.

${ }^{48}$ P. Sherwood, A. H. de Vries, M. F. Guest, G. Schreckenbach, C. R. A. Catlow, S. A. French, A. A. Sokol, S. T. Bromley, W. Thiel, A. J. Turner et al., "QUASI: A general purpose implementation of the QM/MM approach and its application to problems in catalysis," J. Mol. Struct.: THEOCHEM 632, 1-28 (2003).

${ }^{49}$ S. Metz, J. Kästner, A. A. Sokol, T. W. Keal, and P. Sherwood, "ChemShellA modular software package for QM/MM simulations,” Wiley Interdiscip. Rev.: Comput. Mol. Sci. 4, 101-110 (2014).

${ }^{50}$ Y. Zhao and D. G. Truhlar, "The M06 suite of density functionals for main group thermochemistry, thermochemical kinetics, noncovalent interactions, excited states, and transition elements: Two new functionals and systematic testing of four M06-class functionals and 12 other functionals," Theor. Chem. Acc. 120, 215-241 (2008).

${ }^{51}$ F. Weigend, M. Häser, H. Patzelt, and R. Ahlrichs, "RI-MP2: Optimized auxiliary basis sets and demonstration of efficiency," Chem. Phys. Lett. 294, 143-152 (1998).

${ }^{52}$ J. Kästner, J. M. Carr, T. W. Keal, W. Thiel, A. Wander, and P. Sherwood, "DLFIND: An open-source geometry optimizer for atomistic simulations," J. Phys. Chem. A 113, 11856-11865 (2009).

${ }^{53} \mathrm{G}$. Henkelman and H. Jónsson, "A dimer method for finding saddle points on high dimensional potential surfaces using only first derivatives," J. Chem. Phys. 111, 7010-7022 (1999).

${ }^{54}$ J. Kästner and P. Sherwood, "Superlinearly converging dimer method for transition state search," J. Chem. Phys. 128, 014106 (2008).

${ }^{55} \mathrm{~J}$. Meisner, M. N. Markmeyer, M. U. Bohner, and J. Kästner, "Comparison of classical reaction paths and tunneling paths studied with the semiclassical instanton theory," Phys. Chem. Chem. Phys. 19, 23085-23094 (2017).

${ }^{56}$ H. P. Hratchian and H. B. Schlegel, "Accurate reaction paths using a Hessian based predictor-corrector integrator,” J. Chem. Phys. 120, 9918-9924 (2004).

${ }^{57}$ T. B. Adler, G. Knizia, and H.-J. Werner, "A simple and efficient CCSD (T)-F12 approximation,” J. Chem. Phys. 127, 221106 (2007).

${ }^{58}$ G. Knizia, T. B. Adler, and H.-J. Werner, "Simplified CCSD (T)-F12 methods: Theory and benchmarks," J. Chem. Phys. 130, 054104 (2009).

${ }^{59}$ K. A. Peterson, T. B. Adler, and H.-J. Werner, "Systematically convergent basis sets for explicitly correlated wavefunctions: The atoms $\mathrm{H}, \mathrm{He}, \mathrm{B}-\mathrm{Ne}$, and Al-Ar," J. Chem. Phys. 128, 084102 (2008).

${ }^{60}$ H.-J. Werner, P. J. Knowles, G. Knizia, F. R. Manby, and M. Schütz, "Molpro: A general-purpose quantum chemistry program package," Wiley Interdiscip. Rev.: Comput. Mol. Sci. 2, 242-253 (2012).

${ }^{61}$ C. Arasa, S. Andersson, H. Cuppen, E. F. van Dishoeck, and G.-J. Kroes, "Molecular dynamics simulations of the ice temperature dependence of water ice photodesorption," J. Chem. Phys. 132, 184510 (2010).

${ }^{62}$ A. Fredon, T. Lamberts, and H. Cuppen, "Energy dissipation and nonthermal diffusion on interstellar ice grains," Astrophys. J. 849, 125 (2017).

${ }^{63} \mathrm{D}$. Talbi, G. Chandler, and A. Rohl, "The interstellar gas-phase formation of $\mathrm{CO}_{2}$-Assisted or not by water molecules?," Chem. Phys. 320, 214-228 (2006). 
${ }^{64}$ K. I. Öberg, A. Boogert, K. M. Pontoppidan, G. A. Blake, N. J. Evans, F. Lahuis, and E. F. van Dishoeck, "The c2d Spitzer spectroscopic survey of ices around lowmass young stellar objects. III. $\mathrm{CH}_{4}$," Astrophys. J. 678, 1032-1041 (2008).

${ }^{65}$ A. Bieler, K. Altwegg, H. Balsiger, A. Bar-Nun, J.-J. Berthelier, P. Bochsler, C. Briois, U. Calmonte, M. Combi, J. De Keyser et al., "Abundant molecular oxygen in the coma of comet 67P/Churyumov-Gerasimenko," Nature 526, 678 (2015).

${ }^{66}$ V. Taquet, K. Furuya, C. Walsh, and E. F. van Dishoeck, "A primordial origin for molecular oxygen in comets: A chemical kinetics study of the formation and survival of $\mathrm{O}_{2}$ ice from clouds to discs," Mon. Not. R. Astron. Soc. 462, S99-S115 (2016).
${ }^{67}$ D. Qasim, G. Fedoseev, K.-J. Chuang, V. Taquet, T. Lamberts, J. He, S. Ioppolo, E. F. van Dishoeck, and H. Linnartz, "Formation of interstellar propanal and 1-propanol ice: A pathway involving solid-state $\mathrm{CO}$ hydrogenation," Astron. Astrophys. 627, A1 (2019).

${ }^{68} \mathrm{~J}$. R. Martínez-Galarza et al., Mid-Infrared Spectroscopy of Starbursts: From Spitzer-IRS to JWST-MIRI (Leiden Observatory, Faculty of Science, Leiden University, 2012).

${ }^{69}$ J. T. van Scheltinga, N. Ligterink, A. Boogert, E. F. van Dishoeck, and H. Linnartz, "Infrared spectra of complex organic molecules in astronomically relevant ice matrices-I. Acetaldehyde, ethanol, and dimethyl ether," Astron. Astrophys. 611, A35 (2018). 